\title{
Characterization of Pulmonary Venous Hypertension Patients with Reactive Pulmonary Hypertension as Compared to Proportional Pulmonary Hypertension
}

\author{
Gidon Berger a, b, d Emilia Hardak ${ }^{a, d}$ Waleed Obaid $^{d}$ Beatrice Shaham $^{\mathrm{a}}$ \\ Shemi Carasso ${ }^{c}$ Arthur Kerner ${ }^{c}$ Mordechai Yigla ${ }^{a} d$ Zaher S. Azzam ${ }^{b, d, e}$ \\ ${ }^{a}$ Division of Pulmonary Medicine, ${ }^{\mathrm{b}}$ Department of Internal Medicine B, and ${ }^{\mathrm{C} H e a r t ~ I n s t i t u t e, ~ R a m b a m ~ H e a l t h ~ C a r e ~}$ \\ Campus, ${ }^{d}$ Ruth and Bruce Rappaport Faculty of Medicine, and ${ }^{\mathrm{e}}$ The Rappaport Family Institute for Research in the \\ Medical Sciences, Technion, Israel Institute of Technology, Haifa, Israel
}

\section{Key Words}

Pulmonary hypertension - Pulmonary vascular resistance • Pulmonary venous hypertension • Pulmonary capillary wedge pressure $\cdot$ Right heart catheterization •

Transpulmonary gradient

\begin{abstract}
Background: Patients with pulmonary venous hypertension (PVH) secondary to left heart disease can be further classified according to their hemodynamic profile: pulmonary hypertension $(\mathrm{PH})$ in proportion to the pulmonary capillary wedge pressure (PCWP) and $\mathrm{PH}$ out of proportion to the $\mathrm{PCWP}$ or reactive $\mathrm{PH}$. Currently, there are no measures that enable prediction of the development of reactive $\mathrm{PH}$ in patients with left heart disease. Objectives: In this study, we aim to characterize $\mathrm{PVH}$ patients with reactive $\mathrm{PH}$ as compared to proportional $\mathrm{PH}$ in an attempt to create a distinct profile for patients with left heart disease carrying a high risk for the development of reactive PH. Methods: Thirty-three $\mathrm{PVH}$ patients with reactive $\mathrm{PH}$ and $29 \mathrm{PVH}$ patients with proportional $\mathrm{PH}$ were analyzed retrospectively over a 6-year period. Clinical, laboratory, echocardiographic and hemodynamic parameters were noted and compared between subgroups. Results: There was no significant difference between $\mathrm{PVH}$ patients with reactive and proportional $\mathrm{PH}$ with regard
\end{abstract}

to gender, age ( $65.91 \pm 11.9$ vs. $66.69 \pm 10.5$ years) and body surface area $\left(1.89 \pm 0.24 \mathrm{vs} .1 .9 \pm 0.23 \mathrm{~m}^{2}\right)$. Prevalence of the metabolic syndrome components was similar in both groups. Interestingly, PCWP was similar in both groups, as were the structural and functional parameters of the left heart. Conclusions: $\mathrm{PVH}$ patients with reactive $\mathrm{PH}$ have a similar profile as patients with proportional $\mathrm{PH}$; consequently, the evolution of reactive $\mathrm{PH}$ is unpredictable. Therefore, it is imperative that physicians maintain a high index of suspicion for the development of reactive $\mathrm{PH}$ even in the early stage of heart disease.

Copyright $\odot 2011$ S. Karger AG, Basel

\section{Introduction}

Patients diagnosed with pulmonary venous hypertension (PVH) based on the measurement of left-sided filling pressure of $>15 \mathrm{~mm} \mathrm{Hg}$ in right heart catheterization (RHC), falling within group 2 according to the revised clinical classification of pulmonary hypertension $(\mathrm{PH}$; Dana Point meeting 2008) [1], can apparently be separated into two different groups. The first subgroup of pa-

M.Y. and Z.S.A. share senior authorship.

\section{KARGER}

Fax +4161306 1234

E-Mail karger@karger.ch

www.karger.com
(C) 2011 S. Karger AG, Basel

0025-7931/12/0836-0494\$38.00/0

Accessible online at:

www.karger.com/res
Emilia Hardak, MD

Division of Pulmonary Medicine

Rambam Health Care Campus

PO Box 9602, Haifa 31096 (Israel)

Tel.+972 4854 2650,E-Mail e_hardak@rambam.health.gov.il 
tients will produce $\mathrm{PH}$ in proportion to the degree of pulmonary capillary wedge pressure (PCWP) increase and the second subgroup will have $\mathrm{PH}$ out of proportion to the degree of PCWP increase or reactive $\mathrm{PH}$.

There has been increased recognition of $\mathrm{PVH}$ patients in whom PH is apparently out of proportion to their underlying cardiac disease. In fact, there is not as yet universal agreement on what defines these patients. It is unclear whether $\mathrm{PH}$ is triggered by the underlying heart disease (perhaps in addition to a susceptible genetic background) or is completely independent of the underlying disease. Moreover, it is not known whether the presence of higher values of PCWP reflecting more advanced cardiac disease is an obligatory condition for the evolution of reactive $\mathrm{PH}$.

Identifying reactive $\mathrm{PH}$ has major clinical implications as these patients might show faster deterioration and could be potentially offered a pulmonary arterial hypertension (PAH)-specific drug.

Currently, identification of patients with left heart disease prone to develop reactive $\mathrm{PH}$ is impossible.

In this study, we aim to characterize PVH patients with reactive $\mathrm{PH}$ and proportional $\mathrm{PH}$ according to their hemodynamic, clinical and echocardiographic characteristics and to examine whether this specific patient population presents a distinct profile distinguishing them from patients with proportional $\mathrm{PH}$.

\section{Patients and Methods}

\section{Study Population}

Using Prometheus, the Rambam integrated electronic medical records system, we identified all consecutive patients admitted to the Rambam Health Care Campus for RHC, between January 1, 2004 and September 30, 2009. Sixty-two patients were enrolled in the study after being diagnosed with PVH based on the measurement of left-sided filling pressure of $>15 \mathrm{~mm} \mathrm{Hg}$ in RHC.

The study population was further classified according to their hemodynamic profile. The first subgroup (study group 1) included patients with $\mathrm{PH}$ in proportion to the degree of PCWP elevation and their hemodynamic profile yielded a transpulmonary gradient $[\mathrm{TPG}=$ mean pulmonary artery pressure $(\mathrm{MPAP})-\mathrm{PCWP}]<12$ $\mathrm{mm} \mathrm{Hg}$ and pulmonary vascular resistance (PVR) $<3$ Wood units. The second subgroup (study group 2) included patients with $\mathrm{PH}$ out of proportion to the degree of PCWP elevation and a hemodynamic profile yielding TPG $>12 \mathrm{~mm} \mathrm{Hg}$ and PVR $>3$ Wood units.

\section{Design}

The hemodynamic parameters (MPAP, TPG, PVR and PCWP) were obtained from RHC; MPAP and PCWP are measurable variables, PVR and TPG are calculated variables. Results of echocardiography, carried out no more than 3 weeks before the time of the RHC, were obtained. Collected parameters included left ventricular (LV) mass, LV diameter, LV volume, intraventricular septum thickness, LV ejection fraction (EF), and LV diastolic dysfunction grade, $\mathrm{E} / \mathrm{A}$ ratio, deceleration time and left atrium (LA) diameter.

Clinical variables [age, gender, body surface area (BSA)] including medical background (presence of diabetes mellitus, hypertension, dyslipidemia) and laboratory parameters (uric acid level) were retrieved from medical records.

The study was approved by the Ethics Committee of Rambam Health Care Campus.

\section{Right Heart Catheterization}

Right heart catheterization was done with standard technique. A Swan-Ganz catheter was advanced through the right femoral vein into wedge position with inflated balloon and X-ray guidance. Pressures and waves were then recorded during short cessation of breathing. Simultaneous aortic pressures and saturations were recorded.

Then, the balloon was deflated, and the catheter was withdrawn to the pulmonary artery. Cardiac output was measured with cold saline by thermodilution method.

A right-sided pullback was done with measurements of pressures, waves and saturations.

Cardiac output was calculated by the Fick method and vascular resistances were calculated.

Standard Two-Dimensional Echocardiographic Study

Studies were acquired using commercially available echocardiographic systems available at our laboratory, with a $3.5-\mathrm{MHz}$ ultrasound probe.

These included Sequoia (Siemens Medical Systems, Mountainview, Calif., USA), IE33 (Philips, The Nederland) and Vivid 7 (GE Vingmed, Hortan, Norway) systems.

Two-dimensional echocardiographic Doppler and Doppler tissue imaging parameters were measured according to the guidelines of the American Society of Echocardiography [2]. LVEF was measured using the apical biplane method of disks from apical 2 -chamber and 4-chamber views. LV diastolic function was assessed by mitral inflow early diastolic and atrial velocities (E/A ratio and deceleration time) and graded by using two scales: 1-4 [3] and 1-3 (data not shown) [4].

\section{Statistical Analysis}

The computer software SPSS 15.0 for Windows was used for data analysis. Descriptive statistics included means, standard deviations as well as minimum and maximum range. The $t$ test for independent samples was conducted to compare the differences between the 'out of proportion group' and the 'in proportion group'. Pearson correlations coefficients between the hemodynamic variables were obtained for each group.

\section{Results}

\section{Characteristics of the Study Population}

Sixty-two patients were eligible for the study. The study population was divided into two groups based on TPG and PVR values. Data from 33 PVH patients with reactive $\mathrm{PH}$ was compared with those of $29 \mathrm{PVH}$ patients with proportional $\mathrm{PH}$. 
Table 1. Clinical and laboratory differences between the groups

\begin{tabular}{|c|c|c|c|}
\hline Group & $\begin{array}{l}\text { Reactive } \\
(\mathrm{n}=33)\end{array}$ & $\begin{array}{l}\text { Proportional } \\
(\mathrm{n}=29)\end{array}$ & $\mathrm{p}$ value \\
\hline \multicolumn{4}{|l|}{ Gender } \\
\hline Male & $14(42.4)$ & $14(48.3)$ & \multirow[t]{2}{*}{ NS } \\
\hline Female & $19(57.6)$ & $15(51.7)$ & \\
\hline \multicolumn{4}{|l|}{ Age, years } \\
\hline Mean & $65.91 \pm 11.9$ & $66.69 \pm 10.5$ & \multirow[t]{2}{*}{ NS } \\
\hline Range & $40-85$ & $67-68$ & \\
\hline \multicolumn{4}{|l|}{$\mathrm{BSA}, \mathrm{m}^{2}$} \\
\hline Mean & $1.89 \pm 0.24$ & $1.9 \pm 0.23$ & \multirow[t]{2}{*}{ NS } \\
\hline Range & $1.50-2.64$ & $1.50-2.39$ & \\
\hline \multicolumn{4}{|l|}{ Heart rate } \\
\hline NSR & $20(60.6)$ & $21(72.4)$ & \multirow[t]{2}{*}{ NS } \\
\hline $\mathrm{AF}$ & $13(39.4)$ & $8(27.6)$ & \\
\hline \multicolumn{4}{|l|}{$\mathrm{DM}, \%$} \\
\hline No & $16(48.5)$ & $13(48.1)$ & \multirow[t]{2}{*}{ NS } \\
\hline Yes & $13(44.8)$ & $14(51.9)$ & \\
\hline \multicolumn{4}{|c|}{ Dyslipidemia, \% } \\
\hline No & $16(48.5)$ & $11(48.0)$ & \multirow[t]{2}{*}{ NS } \\
\hline Yes & $17(51.5)$ & $18(62.0)$ & \\
\hline \multicolumn{4}{|l|}{ HTN, \% } \\
\hline No & $8(27.6)$ & $8(29.6)$ & \multirow[t]{2}{*}{ NS } \\
\hline Yes & $21(72.4)$ & $19(70.4)$ & \\
\hline \multicolumn{4}{|c|}{ Diuretic treatment, \% } \\
\hline No & $10(35.7)$ & $12(46.2)$ & \multirow[t]{2}{*}{ NS } \\
\hline Yes & $18(64.3)$ & $14(53.8)$ & \\
\hline \multicolumn{4}{|c|}{ Uric acid, mg/dl } \\
\hline Mean & $6.2 \pm 2.24$ & $7.0 \pm 2.67$ & \multirow[t]{2}{*}{ NS } \\
\hline Range & $1.5-10.90$ & $1.93-10.90$ & \\
\hline
\end{tabular}

Figures in parentheses are percentages. NS = Not significant; $\mathrm{NSR}=$ normal sinus rhythm; $\mathrm{AF}=$ atrial fibrillation; $\mathrm{DM}=$ diabetes mellitus; HTN = hypertension.

\section{Clinical and Laboratory Characteristics}

The clinical data are presented in table 1. BSA was slightly above the upper limit of normal. There was no significant difference between both groups with regard to gender, age and BSA. The prevalence of diabetes mellitus, hypertension and dyslipidemia was similar in both groups. A mild degree of hyperuricemia was found in both groups.

\section{Echocardiographic Characteristics}

As presented in table 2, LV diameter, LV end-diastolic volume and intraventricular septum thickness were within the normal range and similar in both groups. LV mass was increased in both groups and tended to be larger in group 2; however, it was not statistically significant. Mild LA dilatation and borderline systolic function were noted in both groups. E/A ratio and deceleration time,
Table 2. Echocardiography differences between the groups

\begin{tabular}{|c|c|c|c|}
\hline Group & $\begin{array}{l}\text { Reactive } \\
(\mathrm{n}=33)\end{array}$ & $\begin{array}{l}\text { Proportional } \\
(\mathrm{n}=29)\end{array}$ & $\mathrm{p}$ value \\
\hline \multicolumn{4}{|l|}{ LV mass, $g$} \\
\hline Mean & $198.96 \pm 75.49$ & $223.82 \pm 98.33$ & NS \\
\hline Range & $60-411$ & $107-434$ & \\
\hline \multicolumn{4}{|c|}{ LV diameter, $\mathrm{cm}$} \\
\hline Mean & $5.17 \pm 0.83$ & $5.36 \pm 0.82$ & NS \\
\hline Range & $3.80-6.80$ & $4.10-7.50$ & \\
\hline \multicolumn{4}{|c|}{$\mathrm{LV}$ volume, $\mathrm{ml}$} \\
\hline Mean & $122.93 \pm 57.18$ & $143.68 \pm 53.02$ & NS \\
\hline Range & $18-239$ & $74-298$ & \\
\hline \multicolumn{4}{|c|}{ IVS thickness, $\mathrm{cm}$} \\
\hline Mean & $1.05 \pm 0.32$ & $1.06 \pm 0.19$ & NS \\
\hline Range & $0.60-1.80$ & $0.67-1.50$ & \\
\hline \multicolumn{4}{|c|}{ LA diameter, $\mathrm{cm}$} \\
\hline Mean & $4.69 \pm 0.59$ & $4.62 \pm 0.77$ & NS \\
\hline Range & $3.50-5.50$ & $3.00-6.90$ & \\
\hline \multicolumn{4}{|l|}{ LVEF, \% } \\
\hline Mean & $51.7 \pm 17.6$ & $51.9 \pm 18.2$ & NS \\
\hline Range & $10-81$ & $10-80$ & \\
\hline \multicolumn{4}{|l|}{$\mathrm{E} / \mathrm{A}$} \\
\hline Mean & $1.83(\mathrm{n}=18)$ & $2.08(\mathrm{n}=20)$ & NS \\
\hline Range & $0.4-5.3$ & $0.7-4.6$ & \\
\hline \multicolumn{4}{|c|}{ Deceleration time, ms } \\
\hline Mean & 167.3 & 179.7 & NS \\
\hline Range & $106-325$ & $100-308$ & \\
\hline
\end{tabular}

NS = Not significant; IVS $=$ interventricular septum. $\alpha \leq 0.05$.

reflecting diastolic dysfunction severity, were similar in both groups.

The hemodynamic data are presented in table 3 .

\section{Correlates of PCWP}

In both groups, LA diameter $(\mathrm{r}=0.59, \mathrm{p}=0.01$ for study group 1 , and $\mathrm{r}=0.45, \mathrm{p}=0.01$ for study group 2 ), $\operatorname{MPAP}(\mathrm{r}=0.92, \mathrm{p}=0.001$ and $\mathrm{r}=0.71, \mathrm{p}=0.000$, respectively) and $\mathrm{E} / \mathrm{A}$ ratio $(\mathrm{r}=0.39, \mathrm{p}=0.01)$ correlated with PCWP. No correlation was found between PCWP and TPG, PVR, LV mass, LV diameter, LV volume, intraventricular septum thickness or LVEF.

\section{Correlates of MPAP}

No correlation was found between MPAP and EF. MPAP correlated with LA diameter $(\mathrm{r}=0.58, \mathrm{p}=0.001)$ and obviously with PVR $(r=0.48, p=0.008)$ and TPG $(\mathrm{r}=0.65, \mathrm{p}=0.001)$. Importantly, MPAP correlated with E/A ratio in the proportional $\mathrm{PH}$ group $(\mathrm{r}=0.61, \mathrm{p}=$ 0.004); however, no correlation was found between MPAP and $\mathrm{E} / \mathrm{A}$ ratio in the reactive $\mathrm{PH}$ group. 
Table 3. Hemodynamic differences between the groups

\begin{tabular}{|c|c|c|c|}
\hline Group & $\begin{array}{l}\text { Reactive } \\
(\mathrm{n}=33)\end{array}$ & $\begin{array}{l}\text { Proportional } \\
(n=29)\end{array}$ & $\mathrm{p}$ value \\
\hline \multicolumn{4}{|c|}{ PCWP, mm Hg } \\
\hline Mean & $26.85 \pm 6.65$ & $26.9 \pm 8.34$ & NS \\
\hline Range & $16-40$ & $16-47$ & \\
\hline \multicolumn{4}{|c|}{ TPG, mm Hg } \\
\hline Mean & $20.18 \pm 6.20$ & $8.86 \pm 3.4$ & 0.000 \\
\hline Range & $13-45$ & $3-15$ & \\
\hline \multicolumn{4}{|c|}{ PVR, Wood units } \\
\hline Mean & $5.49 \pm 2.32$ & $1.93 \pm 0.68$ & 0.000 \\
\hline Range & $2.80-12.50$ & $0.90-3.10$ & \\
\hline \multicolumn{4}{|c|}{ MPAP, mm Hg } \\
\hline Mean & $47.03 \pm 8.74$ & $35.76 \pm 8.80$ & 0.000 \\
\hline Range & $33-77$ & $22-55$ & \\
\hline
\end{tabular}

NS $=$ Not significant. $\alpha \leq 0.0001$.

\section{Discussion}

Reactive $\mathrm{PH}$ is a prevalent condition in PVH patients ( $>50 \%$ of the study population) without gender predominance.

Clinical parameters such as age, gender and BSA of $\mathrm{PVH}$ patients with reactive $\mathrm{PH}$ were not different from $\mathrm{PVH}$ patients with proportional $\mathrm{PH}$, indicating that this specific patient population does not exhibit a distinctive clinical pattern.

$\mathrm{PVH}$ is highly associated with the metabolic syndrome [5]. Indeed, the study population had a very high prevalence of hypertension, obesity, diabetes mellitus, hyperuricemia and dyslipidemia. Nevertheless, the prevalence of these conditions was not higher in patients with reactive $\mathrm{PH}$ suggesting that metabolic syndrome is not playing a role in the evolution of reactive $\mathrm{PH}$.

The MPAP, TPG and PVR values in group 1 were higher than those in group 2 defining this group as reactive $\mathrm{PH}$. Lam et al. [6] found that pulmonary artery systolic pressure derived from Doppler echocardiography increased with PCWP. Similarly, we found a correlation between PCWP and MPAP values within this group. However, PCWP values were similar in both groups and importantly did not correlate with TPG and PVR. These results may shed light onto the pathogenesis of reactive $\mathrm{PH}$. By demonstrating that a high value of PCWP is not required for the unproportional increase in PAP in this group of patients together with the lack of correlation between PCWP and PVR or TPG, we provide new evidence that PCWP does not account for PAP increase beyond the passive backward transmission of the pressure elevation. On the other hand, it was generally agreed upon that for PCWP $>25 \mathrm{~mm} \mathrm{Hg}$, no degree of PH would be considered out of proportion [7]. However, we found that the mean PCWP in patients with proportional $\mathrm{PH}$ is higher, meaning that PAP can be proportional to PCWP even with high values of PCWP. This information, from the opposite direction, confirms the understanding that $\mathrm{PCWP}$ is a marginal contributor to the pathway by which $\mathrm{PH}$ evolves and cannot explain the development of reactive $\mathrm{PH}$ in our patients with PVH. Conceivably, the natural course of $\mathrm{PH}$ in PVH patients is separated from PCWP progression and probably dependent on other mechanisms.

LA dilation is closely related to LV filling pressure and indeed, the only structural or functional parameter found to be in correlation with PCWP (and MPAP) is LA diameter. Therefore, the similar PCWP found in both groups is compatible with similar LA diameter found in both groups.

Next, we evaluated the functional and structural parameters of the left ventricle. Patients in both groups had borderline systolic function, and consistent with previous studies, there was no relationship between LVEF and the level of $\mathrm{PH}[8,9]$. Patients from the two subgroups had a similar degree of diastolic dysfunction based on E/A ratio and deceleration time. In patients with proportional $\mathrm{PH}$, the level of $\mathrm{PH}$ was associated with the grade of diastolic dysfunction, relying on the E/A ratio, similar to previous studies [10]. Interestingly, no correlation was found between MPAP and E/A ratio in the reactive $\mathrm{PH}$ group, indicating the existence of a precapillary component in this group of patients. In addition, one cannot rely on the severity of cardiac disease in order to predict the severity of secondary PH. Furthermore, the gap between the level of systolic dysfunction and the magnitude of PAP suggests that substantial increase in PAP might evolve without clinical evidence already in the early stage of cardiac disease.

Some structural parameters (mass, volume and diameter) of the left ventricle of $\mathrm{PVH}$ patients with reactive $\mathrm{PH}$ were paradoxically better (statistically insignificant). Together with the similar PCWP in both groups, a possible interpretation for this observation is that $\mathrm{PH}$ evolution is not the consequence of the structural heart disease, but due to phenomena mediated by humoral factors.

Consistent with our findings, Lam et al. [6] stated that although PVH contributes to $\mathrm{PH}$, it does not fully account for the severity of $\mathrm{PH}$ in patients with heart failure and preserved EF.

PVR is frequently elevated in patients with chronic LV failure as a result of dysregulation of vascular smooth muscle tone and structural remodeling. These abnormal- 
ities are due, at least in part, to pulmonary vascular endothelial dysfunction that results in impaired nitric oxide availability and increased endothelin-1 expression [11].

Cody et al. [12] found that patients with heart failure had significantly elevated plasma endothelin-1 levels that correlated best with pulmonary artery pressures and PVR, but interestingly, not with several other measures of systemic hemodynamics, including cardiac index and PCWP. This finding implies that the levels of hormones and cytokines contributing to the development of $\mathrm{PH}$ are irrespective to the severity of heart disease similar to our finding that PAP values are irrespective to the severity of heart disease and PCWP. Therefore, the sequence of changes that lead to reactive $\mathrm{PH}$ in genetically susceptible $\mathrm{PVH}$ patients might begin at the early stage of the disease by the impairment of endothelial function, which is associated with impaired release of endothelium-derived vasodilating agents (nitric oxide, prostacyclin) and increased expression of endothelin-1. Reactive $\mathrm{PH}$ is probably triggered by, but not directly associated with, the underlying heart disease.

Few studies have evaluated the role of $\mathrm{PAH}$-specific therapies in patients with heart failure and secondary
$\mathrm{PH}$. Currently, the use of PAH-specific drugs is not recommended. However, these therapies were not selectively targeted to $\mathrm{PVH}$ patients with reactive $\mathrm{PH}$ [13-15]. Our findings provide indirect evidence that endothelial dysfunction is the mechanism leading to reactive $\mathrm{PH}$. Therefore, a therapeutic strategy directed towards enhancing nitric oxide-dependent, cyclic GMP-mediated pulmonary vasodilatation through inhibition of the breakdown of cyclic GMP by phosphodiesterase type 5 or antagonizing endothelin-1 effects by endothelin receptor antagonist, implemented exclusively in this specific patient population, may produce better results.

The evolution of reactive $\mathrm{PH}$ in $\mathrm{PVH}$ patients is independent of PCWP values, the severity of cardiac disease, clinical characteristics or the presence of metabolic syndrome.

We conclude that reactive $\mathrm{PH}$ is actually a precapillary form of $\mathrm{PH}$.

Conceivably, activation of hormonal systems triggered by left heart disease and genetic susceptibility leading to functional and/or structural abnormalities of the PA bed delineate the course of the disease in this group of patients.

\section{References}

1 Simonneau G, Robbins I, Beghetti M, et al: Updated clinical classification of pulmonary hypertension. J Am Coll Cardiol 2009; 54(suppl 1):S43-S54.

-2 Lang RM, Bierig M, Devereux RB, Flachskampf FA, Foster E, Pellikka PA, Picard MH, Roman MJ, Seward J, Shanewise JS, Solomon SD, Spencer KT, Sutton M, Stewart WJ: Recommendations for chamber quantification: a report from the American Society of Echocardiography's Guidelines and Standards Committee and the Chamber Quantification Writing Group. J Am Soc Echocardiogr 2005;18:1440-1463.

-3 Nagueh SF, Appleton CP, Gillebert TC, Marino PN, Oh JK, Smiseth OA, Waggoner AD, Flachskampf FA, Pellikka PA, Evangelista A Recommendations for the evaluation of left ventricular diastolic function by echocardiography. J Am Soc Echocardiogr 2009;22: 107-133.

-4 Nagueh SF, Appleton CP, Gillebert TC, Marino PN, Oh JK, Smiseth OA, Waggoner AD, Flachskampf FA, Pellikka PA, Evangelista A: Recommendations for the evaluation of left ventricular diastolic function by echocardiography. Eur J Echocardiogr 2009; 10:165193.

$\checkmark 5$ Robbins IM, Newman JH, Johnson RF Hemnes AR, Fremont RD, Piana RN, Zhao
DX, Byrne DW: Association of the metabolic syndrome with pulmonary venous hypertension. Chest 2009;136:31-36.

-6 Lam CSP, Roger VL, Rodeheffer RJ, Borlaug BA, Enders FT, Redfield MM: Pulmonary hypertension in heart failure with preserved ejection fraction: a communitybased study. J Am Coll Cardiol 2009;53: 1119-1126.

7 Mathier MA: Pulmonary hypertension in heart failure. Medscape Pulmonary Medicine 2008.

8 Butler J, Chomsky DB, Wilson JR: Pulmonary hypertension and exercise intolerance in patients with heart failure. J Am Coll Cardiol 1999;34:1802-1806.

-9 Kraemer MD, Kubo SH, Rector TS, Brunsvold N, Bank AJ: Pulmonary and peripheral vascular factors are important determinants of peak exercise oxygen uptake in patients with heart failure. J Am Coll Cardiol 1993;21:641-648.

10 Neuman Y, Kotliroff A, Bental T, Siegel R, David D, Lishner M: Pulmonary artery pressure and diastolic dysfunction in normal left ventricular systolic function. Int J Cardiol 2008; $127: 174-178$

11 Moraes DL, Colucci WS, Givertz MM: Secondary pulmonary hypertension in chronic heart failure. The role of the endothelium in pathophysiology and management. Circulation 2000;102:1718.

-12 Cody RJ, Haas GJ, Binkley PF, Capers Q, Kelley R: Plasma endothelin correlates with the extent of pulmonary hypertension in patients with chronic congestive heart failure. Circulation 1992;85:504-509.

13 Packer M, McMurray J, Massie BM, Caspi A Charlon V, Cohen-Solal A, Kiowski W, Kostuk W, Krum H, Levine B, Rizzon P, Soler J, Swedberg K, Anderson S, Demets DL: Clinical effects of endothelin receptor antagonism with bosentan in patients with severe chronic heart failure: results of a pilot study. J Card Fail 2005;11:12-20.

14 Kalra PR, Moon JC, Coats AJ: Do results of the ENABLE (Endothelin Antagonist Bosentan for Lowering Cardiac Events in Heart Failure) study spell the end for non-selective endothelin antagonism in heart failure? Int J Cardiol 2002;85:195-197.

15 Lewis GD, Shah R, Shahzad K, Camuso JM, Pappagianopoulos PP, Hung J, Tawakol A, Gerszten RE, Systrom DM, Bloch KD, Semigran MJ: Sildenafil improves exercise capacity and quality of life in patients with systolic heart failure and secondary pulmonary hypertension. Circulation 2007;116:15551562. 